\title{
Intervention Effects of the Health Promotion Programme "Join the Healthy Boat" on Objectively Assessed Sedentary Time in Primary School Children in Germany
}

\author{
Susanne Kobel ${ }^{1, *} \mathbb{\oplus}$, Jens Dreyhaupt ${ }^{2} \mathbb{D}$, Olivia Wartha ${ }^{1}$, Sarah Kettner ${ }^{1}$, Belinda Hoffmann ${ }^{1} \mathbb{C}$ \\ and Jürgen $M$. Steinacker ${ }^{1}$ (D) \\ 1 Division of Sports and Rehabilitation Medicine, Ulm University Hospital, 89075 Ulm, Germany; \\ olivia.wartha@uni-ulm.de (O.W.); sarah.k.weber@gmx.de (S.K.); belinda.hoffmann@uni-ulm.de (B.H.); \\ juergen.steinacker@uniklinik-ulm.de (J.M.S.) \\ 2 Institute for Epidemiology and Medical Biometry, Ulm University, 89075 Ulm, Germany; \\ jens.dreyhaupt@uni-ulm.de \\ * Correspondence: susanne.kobel@uni-ulm.de
}

Received: 20 October 2020; Accepted: 26 November 2020; Published: 3 December 2020

\begin{abstract}
Sedentary behaviour (SB) in children is related to negative health consequences that can track into adulthood. The programme "Join the Healthy Boat" promotes reduced screen time and a less sedentary lifestyle in schoolchildren. This study investigated the effects of the programme on children's SB. For one year, teachers delivered the programme. A total of 231 children (7.0 \pm 0.6 years) participated in the cluster-randomised study; there were 154 one year later at follow-up. Children's SB was assessed using multi-sensor accelerometery, screen time via parental questionnaire. Effects were analysed using (linear) mixed effects regression models. At baseline, children spent $211( \pm 89) \mathrm{min}$ daily in SB, at follow-up $259( \pm 109) \mathrm{min} /$ day with no significant difference between the intervention (IG) and control group (CG). SB was higher during weekends ( $p<0.01$, for CG and IG). However, at follow-up, daily screen time decreased in IG (screen time of $>1 \mathrm{~h}$ /day: baseline: $33.3 \%$ vs. $27.4 \%$; follow-up: $41.2 \%$ vs. $27.5 \%$, for CG and IG, respectively). This multi-dimensional, low-threshold intervention for one year does not seem to achieve a significant reduction in children's SB, although screen time decreased in IG. Therefore, it should be considered that screen time cannot be the key contributor to SB and should not solely be used for changing children's SB. However, if screen time is targeted, interventions should promote the replacement of screen time with active alternatives.
\end{abstract}

Keywords: inactivity; sedentary behaviour; sitting; school-based; childhood

\section{Introduction}

There is ample evidence that regular and sufficient physical activity, as well as low levels of sedentary behaviour, are important for growth and health in school-aged children and youth [1-3], and contribute to the avoidance or limitation of risk of many conditions for chronic or degenerative diseases, which can occur even into adulthood $[4,5]$. Insufficient physical activity and too much sedentary time, on the other hand, have been associated with poor physical and mental health [6-8]. To investigate such associations, it is important to distinguish between sedentary behaviour and physical (in)activity. In adults, sedentary behaviour is associated with an increased risk of chronic conditions, including cardiovascular disease, type 2 diabetes and all-cause mortality [9-12]. In children, an increased risk of obesity, impaired glucose metabolism, cardiovascular disease, high blood pressure and cholesterol, depression and anxiety have been associated with sedentary behaviour $[6-8,13,14]$. 
Although evidence of such associations of sedentary time in children is mainly limited to screen time [6], sedentary behaviour has been shown to track into adolescence and adulthood [15,16].

Environmental changes and advances in technology, however, have resulted in sedentary behaviour being present within all age groups and settings of daily life. In some countries, children and adolescents spend a substantial amount of their time being sedentary, including screen time [17,18], which incorporates all screen-related activities such as television, DVD/video, smart phones, tablets and playing computer or video games [19]. Furthermore, the recent lockdown measures undertaken by several countries following the COVID-19 pandemic and the distance learning methods resulting from the closure of schools increased the sedentary and screen time among children and adolescents around the world [20].

Whilst, to date, there are no guidelines for overall sedentary time for children, there are recommended time limits for screen time based on prior evidence of poorer health and educational outcomes associated with this particular sedentary behaviour [2,14,21-24]. Whereas Canadian and Australian guidelines suggest limiting sedentary recreational screen time for children aged 5-17 years to no more than $2 \mathrm{~h}$ per day $[25,26]$, the World Health Organization (WHO) thus far has only issued such guidelines for children up to 5 years of age [27]. In Germany, national guidelines for primary school children recommend spending as little time as possible with screen media, with a maximum amount of $60 \mathrm{~min}$ per day [28].

Research shows that children exceed those screen time recommendations [29-34], and studies investigating health outcomes related to screen time indicate that high screen time is associated with increased weight gain and obesity [30,35-39]. Consequently, reducing children's sedentary time (including screen time) may be important for the prevention of chronic diseases even in adulthood [40]. Training interventions concerning the knowledge of the main risk factors for health and the adoption of healthy lifestyles conducted on school-age children, for instance, have previously been shown to be effective [41,42].

In order to do so, in South-West Germany, the setting-based health promotion programme "Join the Healthy Boat" promotes, amongst others, reduced screen media use and a less sedentary lifestyle in primary school children by incorporating activity breaks and offering more physical activity. The teacher-based programme supports and structures already present elements of the daily school routine such as educational lessons, physical activity sessions, and (family) homework. Against the background of the already identified need for early prevention, this research investigated the effectiveness of the programme by objectively assessing primary school children's sedentary time longitudinally.

\section{Materials and Methods}

\subsection{Intervention and Study Design}

The school-based, teacher-centred health promotion programme "Join the Healthy Boat", which was developed as a multi-dimensional intervention using Bartholomew's Intervention Mapping Approach [43,44], is based on Bandura's social cognitive theory [45] and Bronfenbrenner's social ecological model [46]. The state-wide programme uses a train-the-trainer approach to disseminate and to enable primary school teachers to change the school environment as well as their teaching to promote physical activity, a healthy diet, and active leisure time without screen media on a weekly basis in their classrooms with no added lessons. The hereby given intervention materials, which were developed in collaboration with a team of experienced teachers are fully integrated into the school curriculum focusing on health promoting behaviour and environment change. The main focus of this intervention is to promote a healthy and active lifestyle by offering a physical activity friendly environment and action alternatives children can choose from in order to be less sedentary and more active. The teaching units, which were implemented by the classroom teacher on a weekly basis, for one school year include 20 lessons teaching health-relevant topics such as "why does my body need 
physical activity?", increasing awareness, and offering ideas and alternatives for children's leisure time without the use of screen media. Thirteen of those lessons (which can be held more than once) focus on physical activity promotion and a reduction of sedentary behaviour. Additionally, every day, two short activity exercises of five to ten minutes each were introduced into the children's school routine in order to break up sedentary behaviour at school. To also involve parents into the programme, letters and so called family homework were handed out regularly, in order to get children to solve exercises actively together with their parents (further details: see [47]). Teachers recorded their implementation rates and only classes with at least $80 \%$ implementation were included in the sample.

To evaluate the programme in South-West Germany, a prospective, stratified, cluster-randomised, and longitudinal study with an intervention and control group was designed. Stratification of randomisation was carried out on grade level based on information about the distribution of participating teachers within the different schools. Stratification according to number of classes and grade levels was realised on six different levels. Cluster-randomisation was carried out on school level into intervention and control group. More details on the intervention's design, theory-guided development and recruitment can be found elsewhere [44,48]. The University's Ethics Committee approved the study (application no. 126/10), as did the Ministry of Culture and Education and it was conducted in accordance with the declaration of Helsinki. The study is also registered at the German Clinical Trials Register (DRKS-ID: DRKS00000494).

\subsection{Participants}

Participation in the programme was voluntary and participating teachers had to agree with the randomisation process. Children provided their assent, parents their written, informed consent to take part in the study as well as a separate consent for their children to wear a multi-sensor device assessing sedentary time objectively for six consecutive days.

Baseline data of 1947 primary school children (aged 5 to 8 years) taking part in the evaluation of "Join the Healthy Boat" were available; for the collection of objectively assessed sedentary time, a sub-sample of 231 children $(7.0 \pm 0.6$ years, $46 \%$ male, intervention $n=133$, control $n=98,12 \%$ of the whole cohort) was investigated, including those children who agreed to wear a multi-sensor device and showed valid data of at least three days of more than $10 \mathrm{~h}$ of recorded data per day. A total of 154 children provided valid data of their sedentary time one year later at follow-up ( $8.0 \pm 0.6$ years, $46.1 \%$ male, intervention $n=102$, control $n=52,67 \%$ of the baseline sub-sample). Neither the sub-sample who agreed to objective measurements, nor the follow-up sample (sub-sample minus drop-out) differed from the whole sample with regards to age, gender and other socio-economic background data.

After baseline measurements had been taken, the intervention started in the intervention group only, the control group followed the regular school curriculum. Follow-up measurements were taken after one school year, directly after a six-week summer break with no intervention.

\subsection{Measurements}

During a school visit, anthropometric measurements (children's height and body mass) were taken by trained staff to ISAK standards [49] using calibrated electronic scales and a stadiometer (Seca 862 and Seca 213, respectively, Seca Weighing and Measuring Systems, Hamburg, Germany). Children's BMI was calculated and converted to BMI percentiles using national reference values [50]. Subsequently, children were classified into under-/normal weight (percentiles $<90$ ), overweight (percentiles $\geq 90$ ) and obese (percentiles $\geq 97$ ).

Sedentary time was assessed using a multi-sensor device (Actiheart ${ }^{\circledR}$, CamNtech, Cambridge, UK), which was validated for children [51]. The chest-fitted sensor was worn for $24 \mathrm{~h}$ a day on six consecutive days. Recording intervals were set to 15 secs and to be included in the sample, at least $10 \mathrm{~h}$ per day including at least two weekdays and one weekend day had to be available [52]. First and last day of recording were excluded from the analysis (in order to antagonise a novelty 
factor on the first day, the last day never showed $10 \mathrm{~h}$ of recording). Heart rate and one-dimensional bodily acceleration were recorded. Energy expenditure (MET) was calculated using Actiheart ${ }^{\circledR}$ 's captive software [53]. Sedentary time was defined as "any waking behaviour characterised by energy expenditure $\leq 1.5$ metabolic equivalents (METs)" [54]. Individual sleeping time was determined for every analysed day by an obvious increase and drop of heart rate for the point of awakening and falling asleep, respectively. This was subsequently subtracted from daily assessed recording time to quantify children's sedentary time during waking hours only. In order to calculate total sedentary time, the available days were extrapolated to a full week, using a ratio of 5:2 for weekdays and weekend days.

Children's screen time (including time spent with television and computer/game console) for weekdays and weekend days as well as their socio-demographic information were collected via a parental questionnaire. The included questions were based on the German Health Interview and Examination Survey for Children and Adolescents, which assessed health behaviour in 18,000 German children and adolescents [55]. Screen time was assessed as an ordinal variable with seven categories and dichotomised according to national guidelines [28] into one hour or less and more than one hour. Parental education level was determined based on the highest school education of either one parent or the single parent and thereafter dichotomised into tertiary education level (high school) and primary/secondary education level. Children were classed as having a migration background if at least one parent was born abroad or the child was spoken to in a foreign language during the first three years of life.

\subsection{Data Analyses}

Linear mixed-effects regression models and mixed-effects regression models for a binary outcomes were used to analyse group differences and in the examination of differences between weekdays and weekend days. Gender differences were also examined using mixed-effects regression models adjusting for age and BMI percentiles. Intervention effects were analysed using linear mixed effects regression models as well as mixed effects regression models for binary outcomes, controlling for age, gender, BMI percentiles, migration background, family education level, and baseline values. Descriptive statistics for continuous variables were displayed in mean values and standard deviations. Categorical variables were described with absolute and relative frequencies. To detect differences between the groups and samples, the two-sample t-test was used for continuous data, the chi ${ }^{2}$ test or Fisher's exact test was used for binary data. Statistical analyses were performed using SPSS Statistics 25 (SPSS Inc., Chicago, IL, US) and SAS, version 9.4 (SAS Institute, Cary, NC, US) with a two-sided significance level set to $\alpha \leq 0.05$.

\section{Results}

A summary of participant's descriptive data can be found in Table 1. There was no difference regarding age, body weight and height, BMI percentiles, migration background, and parental education level between the here analysed sub-sample, who agreed to objective activity assessment and total sample, nor between control and intervention group (descriptive data of the whole sample were published elsewhere [56]).

Table 1. Descriptive characteristics of total sample, control and intervention group at follow-up.

\begin{tabular}{ccccc}
\hline Variables & $\begin{array}{c}\text { Missing } \\
\text { Values }\end{array}$ & $\begin{array}{c}\text { Total Sample } \\
(\boldsymbol{n}=\mathbf{1 5 4})\end{array}$ & $\begin{array}{c}\text { Control } \\
(\boldsymbol{n}=\mathbf{5 2})\end{array}$ & $\begin{array}{c}\text { Intervention } \\
(\boldsymbol{n}=\mathbf{1 0 2})\end{array}$ \\
\hline Gender (male); $n(\%)$ & 0 & $71(46.1)$ & $22(42.3)$ & $49(48.0)$ \\
\hline Age (years); $\mathrm{m} \pm \mathrm{SD}$ & 0 & $8.0 \pm 0.6$ & $8.0 \pm 0.6$ & $8.0 \pm 0.7$ \\
\hline Height $(\mathrm{cm}) ; \mathrm{m} \pm \mathrm{SD}$ & 0 & $129.5 \pm 6.5$ & $129.9 \pm 6.5$ & $129.2 \pm 6.5$ \\
\hline Weight $(\mathrm{kg}) ; \mathrm{m} \pm \mathrm{SD}$ & 1 & $27.0 \pm 4.9$ & $26.7 \pm 3.5$ & $27.2 \pm 5.4$ \\
\hline
\end{tabular}


Table 1. Cont.

\begin{tabular}{ccccc}
\hline Variables & $\begin{array}{c}\text { Missing } \\
\text { Values }\end{array}$ & $\begin{array}{c}\text { Total Sample } \\
(\boldsymbol{n}=\mathbf{1 5 4})\end{array}$ & $\begin{array}{c}\text { Control } \\
(\boldsymbol{n}=\mathbf{5 2})\end{array}$ & $\begin{array}{c}\text { Intervention } \\
(\boldsymbol{n}=\mathbf{1 0 2})\end{array}$ \\
\hline BMIPCT m \pm SD & 1 & $45.5 \pm 26.6$ & $44.0 \pm 23.4$ & $46.3 \pm 28.2$ \\
\hline Weight status & & & & \\
\hline Overweight/Obese; $n(\%)$ & 1 & $10(6.5)$ & $1(1.9)$ & $9(8.8)$ \\
Migration background; $n(\%)$ & 20 & $37(27.6)$ & $9(19.6)$ & $28(31.8)$ \\
High family education level; $n(\%)$ & 25 & $45(34.9)$ & $14(33.3)$ & $31(35.6)$ \\
\hline
\end{tabular}

Values are mean $(\mathrm{m}) \pm$ standard deviation (SD) or numbers $(n)$ and percentages $(\%)$.

\subsection{Sedentary Time}

At baseline, children spent $211( \pm 89)$ min daily in sedentary time; at follow-up this increased to 259 ( \pm 109 ) min per day, with no significant difference between intervention and control group. Sedentary time was significantly higher during weekends, compared to weekdays $(p<0.01$, for control and intervention as well as baseline and follow-up; see Table 2).

Table 2. Time at baseline and follow-up (in rounded min) spent in sedentary time (without sleep) and percentage of children using screen media for more than one hour per day.

\begin{tabular}{|c|c|c|c|c|}
\hline \multirow{2}{*}{ Variables } & \multirow{2}{*}{ Missing Values } & Total Sample & Control & Intervention \\
\hline & & $n=231(\mathrm{~b}), 154(\mathrm{f})$ & $n=98(\mathrm{~b}), 52(\mathrm{f})$ & $n=133(\mathrm{~b}), 102(\mathrm{f})$ \\
\hline \multicolumn{5}{|c|}{ Sedentary Time (min/day) (mean \pm SD $(95 \%$ CI $))$} \\
\hline \multicolumn{5}{|l|}{ Total week } \\
\hline Baseline & 0 & $211 \pm 89(199-222)$ & $219 \pm 87(201-236)$ & $205 \pm 91(189-220)$ \\
\hline Follow-up & 0 & $259 \pm 109(242-276)$ & $254 \pm 99(226-281)$ & $262 \pm 115(239-284)$ \\
\hline \multicolumn{5}{|l|}{ Weekdays } \\
\hline Baseline & 0 & $199 \pm 95(187-212)$ & $207 \pm 92(188-225)$ & $194 \pm 98(177-211)$ \\
\hline Follow-up & 2 & $241 \pm 108(224-258)$ & $240 \pm 102(211-268)$ & $242 \pm 112(219-264)$ \\
\hline \multicolumn{5}{|l|}{ Weekend } \\
\hline Baseline & 0 & $239 \pm 103(226-253)$ & $249 \pm 102(228-269)$ & $233 \pm 104(215-250)$ \\
\hline Follow-up & 1 & $295 \pm 123(275-315)$ & $293 \pm 125(258-328)$ & $296 \pm 124(271-320)$ \\
\hline \multicolumn{5}{|c|}{ Screen Time of $>1$ h/day $(n(\%)(95 \%$ CI $))$} \\
\hline \multicolumn{5}{|l|}{ Total week } \\
\hline Baseline & 31 & $60(30.0)(23.7-36.9)$ & $29(33.3)(23.6-44.3)$ & $31(27.4)(19.5-36.6)$ \\
\hline Follow-up & 12 & $46(32.4)(24.8-40.8)$ & $21(41.2)(27.6-55.8)$ & $25(27.5)(18.6-37.8)$ \\
\hline \multicolumn{5}{|l|}{ Weekdays } \\
\hline Baseline & 31 & $15(7.5)(4.3-12.1)$ & $11(12.6)(6.5-21.5)$ & $4(3.5)(1.0-8.8)$ \\
\hline Follow-up & 12 & $10(7.0)(3.4-12.6)$ & $2(3.9)(0.5-13.5)$ & $8(8.8)(3.9-16.6)$ \\
\hline \multicolumn{5}{|l|}{ Weekend } \\
\hline Baseline & 30 & $93(46.3)(39.2-53.4)$ & $39(44.8)(34.2-55.9)$ & $54(47.4)(37.9-56.9)$ \\
\hline Follow-up & 12 & $77(54.2)(45.7-62.6)$ & $32(62.8)(48.1-75.9)$ & $45(49.5)(38.8-60.1)$ \\
\hline
\end{tabular}

Values are mean $(\mathrm{m}) \pm$ standard deviation (SD) and $95 \%$ confidence interval (CI) or numbers $(n)$ and percentages $(\%)$ and $95 \%$ confidence interval (CI). (b) Baseline; (f) follow-up.

At follow-up, no gender difference was observed for total sedentary time, nor was there a gender difference for sedentary time at weekdays and weekends, separately. Similarly, children's weight status was not associated with differences in objectively assessed sedentary time. Children of parents with tertiary-level education (compared to primary- and secondary-level education), however, showed significantly more sedentary time on weekdays ( $285 \pm 112 \mathrm{~min} /$ day vs. $225 \pm 96 \mathrm{~min} /$ day, 
$p=0.01$ ), but not on weekends or during the total week. On the other hand, having a migration background was significantly associated with more sedentary time at the weekend (346 $\pm 138 \mathrm{~min} /$ day vs. $276 \pm 110 \mathrm{~min} /$ day, $p<0.01$ ), but not at weekdays or during the total week.

Further, the final mixed effects regression model controlling for baseline values showed no significant intervention effects on total sedentary time, sedentary time at weekdays and on weekends for the total sample, nor for screen time (Table 3). When controlling for baseline values, gender, migration background as well as weight status and family education level, different results were only found for daily screen time during the whole week $(p=0.02)$.

Table 3. Final mixed effects regression model for binary outcomes.

\begin{tabular}{|c|c|c|c|}
\hline \multirow{2}{*}{ Variables } & \multicolumn{3}{|c|}{ Total Sample $(n=154)$} \\
\hline & $n$ & Estimate (CI 95\%) & $p$ \\
\hline \multicolumn{4}{|c|}{ Sedentary Time incl. baseline and intervention/control group } \\
\hline Total week & 100 & $-35.6(-91.1 ; 20.0)$ & 0.21 \\
\hline Weekdays & 99 & $-23.4(-87.6 ; 40.8)$ & 0.47 \\
\hline Weekend & 99 & $-22.0(-87.9 ; 43.9)$ & 0.51 \\
\hline \multicolumn{4}{|c|}{ Screen Time of $>1 \mathrm{~h} /$ day incl. baseline and intervention/control group } \\
\hline Total week & 130 & $0.13(-0.02 ; 0.29)$ & 0.08 \\
\hline Weekdays & 130 & $-0.04(-0.13 ; 0.05)$ & 0.42 \\
\hline Weekend & 130 & $0.08(-0.09 ; 0.24)$ & 0.36 \\
\hline
\end{tabular}

\subsection{Daily Screen Time}

At baseline, $30.0 \%(n=200$, missing $=31)$ children spent more than one hour daily with screen media, with a significant difference between control and intervention group for daily screen time. At follow-up this amount increased to $32.4 \%(n=46$; see Table 2$)$, with a significant difference between intervention and control group for daily screen time. Daily screen time was significantly higher during weekends, compared to weekdays $(p<0.01$, for control and intervention as well as baseline and follow-up).

At follow-up, when assessed via mixed model analyses, parent reported daily screen time decreased in the intervention group, compared to the control group (daily screen media use of $<1 \mathrm{~h}$ : $41.2 \%$ vs. $27.5 \%$, for control and intervention group, respectively). This is especially visible (even though not significant) on weekends ( $62.8 \%$ vs. $49.5 \%$, for control and intervention group, respectively).

Assessing change for one year (as shown in Figure 1), most of the children in control and intervention group did not change their screen time behaviour. A total of $73.3 \%$ of children in the control group and $77.6 \%$ of children in the intervention group showed the same amount of screen time at baseline and at follow-up. Additionally, $10.6 \%$ of children in the intervention group decreased their daily screen time, whereas $8.9 \%$ of children in the control group used less screen media at follow-up. Respectively, $11.8 \%$ of children in the intervention group increased their screen time at follow-up compared to $17.8 \%$ in the control group.

Further, there was a significant difference in children using screen media for more than one hour daily when comparing weekdays with weekends $(\mathrm{F}=9.70, p<0.01)$, as well as for gender with boys reporting significantly higher screen times than girls $(\mathrm{F}=5.90, p=0.02)$. Moreover, screen times of children with migration background differed significantly from those without migration background. Children with migration background showed significantly more often screen times of more than one hour per day compared to children without migration background ( $\mathrm{F}=4.03, p=0.05)$. 


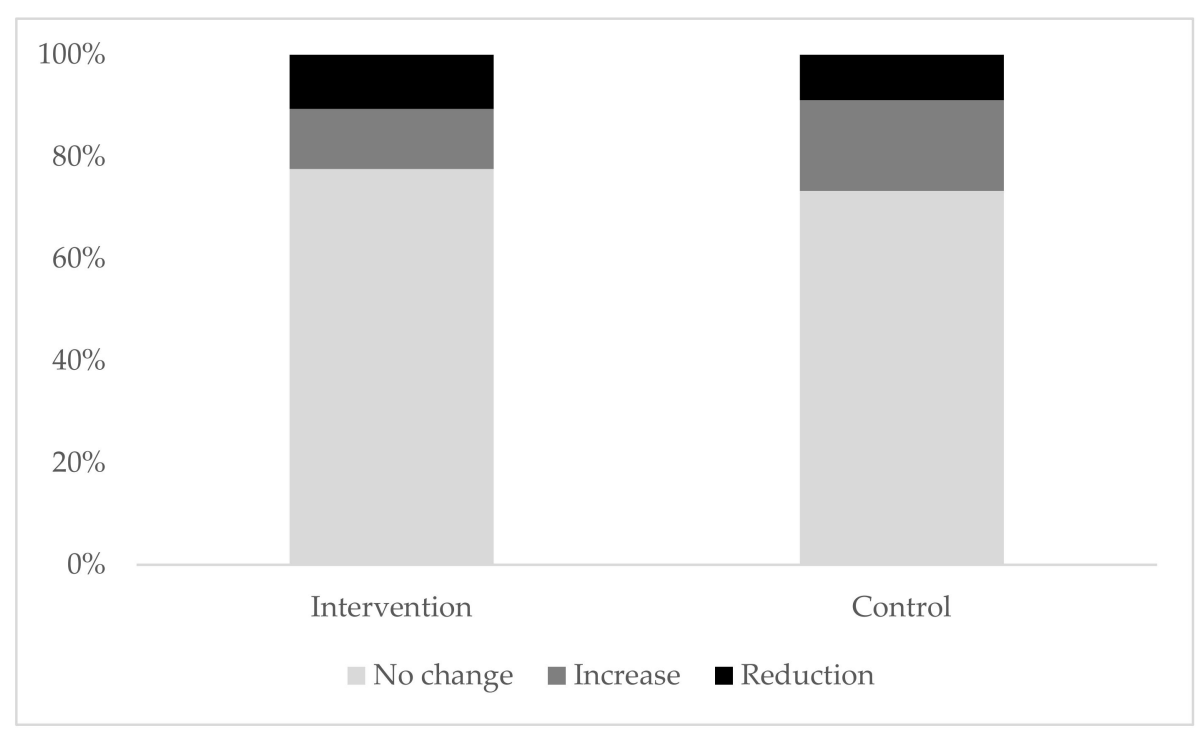

Figure 1. Change in screen time over one year in intervention and control group in percent.

\section{Discussion}

This study aimed to evaluate the effectiveness of the setting-based health-promotion programme "Join the Healthy Boat" on sedentary time in primary school children. After one year, objectively assessed sedentary behaviour of children in the intervention group did not differ from those in the control group. In line with previous research on multi-component school-based interventions [57], sedentary time increased in the space of 12 months; this was especially evident at weekends. This increase is most likely due to the age related incline that is seen in sedentary time during childhood [58] and participation in "Join the Healthy Boat" did not manage to prevent this increase.

The programme intended to tackle sedentary behaviour at school with daily exercise breaks and the offer of action alternatives for children's leisure time so they would refrain from using screen media after school or at the weekends. In order to involve their parents, family homework was issued regularly to encourage "screen free" days or weekends, offered ideas to where to go at the weekend or what games to play to get more physically active and break up sedentary time.

It has previously been suggested that sedentary time can be a predictor of chronic disease independent of physical activity levels [59]. Especially crucial are increased total sedentary time but also prolonged uninterrupted blocks of sedentary time. Both have been addressed in "Join the Healthy Boat" since the introduction of short activity exercises of five to ten minutes each was supposed to break up sedentary time at school, which should have happened in the middle of lessons, so the children were likely to be sitting before and after their exercise breaks. Despite this, this study shows an increase of $48( \pm 20) \mathrm{min}$ in average daily sedentary time, independent of control or intervention group.

A Scottish study has also tried to implement an additional $15 \mathrm{~min}$ of exercise into primary school children's daily classroom routine. In "The Daily Mile" [60], teachers were asked to send the children outside (at a time of the teacher's choosing) so they could exercise for $15 \mathrm{~min}$ at a self-selected pace and break up sedentary time. That intervention showed a significant reduction of sedentary time of around 18 min after half a year, with authors suggesting that children replaced sedentary time with physical activity [60].

More comparable results to the ones reported here were found in a one-year school-based intervention study in the Netherlands [57] as well as a recent Scandinavian study in first graders, intervening on teacher level in an after school care setting [61]. Similar to this study, teachers in Norway were trained to create a physical activity supporting environment in order to promote physical activity and reduce sedentary time. After seven months of intervention, no significant intervention effects were found on sedentary time. Moreover, from baseline to follow-up, total sedentary time in the 
intervention group increased slightly compared to the control group [54], which was observed in this study as well. Possibly a more intense intervention would have shown more effective results, such as seen when replacing standard desks with sit-stand desks [38]. Teachers encouraged children to use those desks for more than one hour per day, which reduced children's weekday sitting time by half an hour after 4.5 months [40].

Here, children accumulated less sedentary time on weekdays compared to weekends, which goes in line with recent results of a large Finnish sample of secondary school children [62]. This was especially true for children with migration background, which has been shown previously [63]. It was argued that children, but more so their parents, are hardly accessible and, therefore, intervening on child and parental level is more difficult. It has also been suggested, that there are significant associations between parental activities and those of their children, including sedentary behaviour [64,65], with mothers' and fathers' time spent sedentary positively correlating with children's sedentary time $[65,66]$. Parental influence on children's health behaviours is a well-known determinant of childhood obesity [67] and a recent review has once more highlighted that parental involvement in addressing health issues such as sedentary behaviour in children is essential [68]. According to the authors, face-to-face meetings with parents appeared to show greater effects compared to handed out written material [68]. In "Join the Healthy Boat", parental involvement was realised by five parent letters in three different languages throughout the year (three of which addressed physical activity and sedentary behaviour), six family homework assignments, and two parents' nights at school. Possibly, a more active and more frequent involvement of parents in joint activities at school or regular face-to-face contact between teachers and parents would have shown more positive effects.

However, since sedentary behaviour was addressed by increasing physical activity (offers) and reducing screen time (in class and with the parents), this might have led to the observed decrease in children spending more than one hour per day with screen media on weekdays. Compared to other European cohorts, Germany shows generally low screen time values [69]; yet, this sample showed very low screen time, even initially. This national cut-off of one hour per day [28] to determine screen time showed that most children adhered to those guidelines, which is unusually high, even when compared with studies using a cut-off of two hours per day [69]. Screen time was assessed via parental questionnaire (as in other large European cohorts [69]) and, therefore, subject to social desirability and recall bias. Nonetheless, the difference in parental-reported screen time of children in the control and intervention group indicates a positive tendency of the programme.

It is well known that screen time is associated to adiposity, quality of life, mental health, and sleep outcomes $[35,70,71]$. Yet it has been shown that high sedentary time is not necessarily due to increased screen time [72,73]. Comparing children with low, medium, and high sedentary time showed no difference in daily screen time but when comparing it to their total sedentary time, percentages ranged between $27 \%$ and $71 \%$ of total sedentary time [73]. Therefore, it should not solely be intervened to reduce children's screen time in order to decrease their sedentary time.

Still, primary schools have previously been described as an ideal setting for interventions to reduce sedentary behaviour through practice, policy, and a supportive environment $[68,74]$; yet, this requires an active involvement not just of parents but also of teachers. This sometimes proves difficult, especially if the teacher's own behaviours do not agree with the messages delivered in the intervention [75]. It has been suggested that school-based interventions are most effective if children have relevant role models-from parents and teachers [68].

One of the challenging aspects of this intervention was the transmission of the lessons' content to children's behaviour at home. As previously mentioned, family involvement was limited to thirteen times during one school year, with hardly any personal contact between teachers and parents. Although, implementation was recorded on teacher level, it is impossible to say whether the parents actually received or read the handed out written information. Further, possibly more individual recommendations on school level, such as school-specific plan for situational prevention worked out jointly with teachers, school head and the project team would have led to greater commitment and 
might have had greater impact on the structural changes schools were offered to make in order to get children more active and to reduce their sedentary time at school. Possibly a one-size-fits-all solution is not necessarily effective at tackling sedentary behaviour in a school setting.

In order to design future health promotion programmes that incorporate all those aspects and implement findings from this research, some limitations have to be considered when interpreting these results. Sedentary behaviour was (although assessed objectively) calculated on the basis of energy expenditure, which might have led to misinterpretations in some children. Screen time, on the other hand, was assessed via parental report and, therefore, as mentioned before, is subject to social desirability and recall bias. Further, due to the voluntary agreement of parents, teachers and children to participate in this study, a selection bias cannot be ruled out, which also led to the results not being representative although the sample was spread over a relatively large area. The sample also showed very low rates of screen time initially, which possibly should have been assessed before trying to intervene in that sample. Besides, it should be noted that follow-up took place after a six-week summer break with no intervention, which might have led to the lack of intervention effects. Additionally, possibly a longer lasting, more intense intervention with extra lessons and especially more alternatives for at home would have shown more positive effects. Furthermore, the lack of intervention effects on children's sedentary time could also be due to the study design. The voluntary participation and the randomisation into intervention and control group might have made control schools susceptible for other health promotion, which may have caused changes in children's sedentary behaviour in the control group. However, this design and its randomisation is also a strength of this study, so it the relatively large sample size and the intervention duration of one year. Additionally, the use of a solid theoretical framework as basis of this intervention should have helped to generate more positive intervention effects [76], as should the combination of implementing environmental changes, the offer of action alternatives and parental involvement [41,77].

\section{Conclusions}

This multi-dimensional, low-threshold intervention for one year does not seem to achieve a significant reduction in children's objectively assessed sedentary time. A more intense or specific intervention providing increased opportunities to break up sedentary time at school and a better transfer to children's homes might possibly have led to positive intervention effects and should be considered for the future. Additionally, sedentary time was higher at weekends, which calls for a greater parental involvement, which should be part of any well-planned health promotion programme. However, parent-reported screen time decreased in the intervention group, which leads to the assumption that screen time cannot be the key contributor to sedentary time and should not solely be used for changing children's sedentary behaviour. Thus, if screen time is targeted, interventions should promote replacing screen time with alternatives in order to get children engaged in more physical activity. Hence, health behaviours need to be changed in more detail and with a greater intensity, especially at the family level, where the delivery of action alternatives and indirect offers for physical activity and the reduction of sedentary time may not take effect.

Author Contributions: Conceptualization, S.K. (Susanne Kobel), O.W., S.K. (Sarah Kettner) and J.M.S.; methodology, S.K. (Susanne Kobel), S.K. (Sarah Kettner) and J.D.; software, S.K. (Susanne Kobel), S.K. (Sarah Kettner) and J.D.; validation, S.K. (Susanne Kobel), S.K. (Sarah Kettner) and J.D.; formal analysis, S.K. (Susanne Kobel), S.K. (Sarah Kettner) and J.D.; investigation, S.K. (Susanne Kobel) and S.K. (Sarah Kettner); resources, S.K. (Susanne Kobel) and O.W.; data curation, S.K. (Susanne Kobel), S.K. (Sarah Kettner) and J.D.; writing — original draft preparation, S.K. (Susanne Kobel); writing-review and editing, S.K. (Susanne Kobel), J.D., O.W., S.K. (Sarah Kettner) B.H. and J.M.S.; visualization, S.K. (Susanne Kobel); supervision, J.M.S.; project administration, S.K. (Susanne Kobel) and O.W.; funding acquisition, J.M.S. All authors have read and agreed to the published version of the manuscript.

Funding: The school-based health promotion programme "Join the Healthy Boat" and its evaluation study were funded by Baden-Württemberg Foundation, grant number BWS_1.479.00_2009, which had no role in the design, execution, interpretation, or writing of the study. 
Acknowledgments: The authors would like to thank all members of the programme "Join the Healthy Boat" for their input, as well as all student assistants who were involved in the performance of measurements, and especially all teachers and families for their participation.

Conflicts of Interest: The authors declare no conflict of interest, since the funder had no role in the design of the study; in the collection, analyses, or interpretation of data; in the writing of the manuscript, or in the decision to publish the results.

\section{References}

1. Poitras, V.J.; Gray, C.E.; Borghese, M.M.; Carson, V.; Chaput, J.-P.; Janssen, I.; Katzmarzyk, P.T.; Pate, R.R.; Gorber, S.C.; Kho, M.E.; et al. Systematic review of the relationships between objectively measured physical activity and health indicators in school-aged children and youth. Appl. Physiol. Nutr. Metab. 2016, 41, S197-S239. [CrossRef]

2. Carson, V.; Hunter, S.; Kuzik, N.; Gray, C.E.; Poitras, V.J.; Chaput, J.-P.; Saunders, T.J.; Katzmarzyk, P.T.; Okely, A.D.; Gorber, S.C.; et al. Systematic review of sedentary behaviour and health indicators in school-aged children and youth: An update. Appl. Physiol. Nutr. Metab. 2016, 41, S240-S265. [CrossRef]

3. Saunders, T.J.; Gray, C.E.; Poitras, V.J.; Chaput, J.-P.; Janssen, I.; Katzmarzyk, P.T.; Olds, T.; Gorber, S.C.; Kho, M.E.; Sampson, M.; et al. Combinations of physical activity, sedentary behaviour and sleep: Relationships with health indicators in school-aged children and youth. Appl. Physiol. Nutr. Metab. 2016, 41, S283-S293. [CrossRef]

4. Panico, A.; Grassi, T.; Bagordo, F.; Idolo, A.; Serio, F.; Tumolo, M.R.; De Giorgi, M.; Guido, M.; Tutino, M.; De Donno, A. Micronucleus frequency in exfoliated buccal cells of children living in an industrialised area of Apuli (Italy). Int. J. Environ. Res. Public Health 2020, 17, 1208. [CrossRef] [PubMed]

5. Dietz, W.H.; Douglas, C.E.; Brownson, R.C. Chronic Disease Prevention: Tobacco Avoidance, Physical Activity, and Nutrition for a Healthy Start. JAMA 2016, 316, 1645-1646. [CrossRef]

6. Carson, V.; Tremblay, M.S.; Chaput, J.-P.; Chastin, S. Associations between sleep duration, sedentary time, physical activity, and health indicators among Canadian children and youth using compositional analyses. Appl. Physiol. Nutr. Metab. 2016, 41, S294-S302. [CrossRef] [PubMed]

7. Biddle, S.J.; Asare, M. Physical activity and mental health in children and adolescents: A review of reviews. Br. J. Sports Med. 2011, 45, 886-895. [CrossRef] [PubMed]

8. Katzmarzyk, P.T.; Staiano, A.E. Relationship Between Meeting 24-Hour Movement Guidelines and Cardiometabolic Risk Factors in Children. J. Phys. Act. Health 2017, 14, 779-784. [CrossRef]

9. Wilmot, E.G.; Edwardson, C.L.; Achana, F.A.; Davies, M.J.; Gorely, T.; Gray, L.J.; Khunti, K.; Yates, T.; Biddle, S.J.H. Sedentary time in adults and the association with diabetes, cardiovascular disease and death: systematic review and meta-analysis. Diabetologia 2012, 55, 2895-2905. [CrossRef]

10. Biswas, A.; Oh, P.I.; Faulkner, G.E.; Bajaj, R.R.; Silver, M.A.; Mitchell, M.S.; Alter, D.A. Sedentary time and its association with risk for disease incidence, mortality, and hospitalization in adults: A systematic review and meta-analysis. Ann. Intern. Med. 2015, 162, 123-132. [CrossRef]

11. Ekelund, U.; Steene-Johannessen, J.; Brown, W.J.; Fagerland, M.W.; Owen, N.; Powell, K.E.; Bauman, A.; Lee, I.-M. Does physical activity attenuate, or even eliminate, the detrimental association of sitting time with mortality? A harmonised meta-analysis of data from more than 1 million men and women. Lancet 2016, 388, 1302-1310. [CrossRef]

12. Patterson, R.; McNamara, E.; Tainio, M.; De Sá, T.H.; Smith, A.D.; Sharp, S.J.; Edwards, P.; Woodcock, J.; Brage, S.; Wijndaele, K. Sedentary behaviour and risk of all-cause, cardiovascular and cancer mortality, and incident type 2 diabetes: A systematic review and dose response meta-analysis. Eur. J. Epidemiol. 2018, 33, 811-829. [CrossRef] [PubMed]

13. De Moraes, A.C.F.; Carvalho, H.B.; Siani, A.; Barba, G.; Veidebaum, T.; Tornaritis, M.; Molnar, D.; Ahrens, W.; Wirsik, N.; De Henauw, S.; et al. Incidence of high blood pressure in children-effects of physical activity and sedentary behaviors: The IDEFICS study: High blood pressure, lifestyle and children. Int. J. Cardiol. 2015, 180, 165-170. [CrossRef] [PubMed]

14. Sivanesan, H.; on behalf of the TARGet Kids! Collaboration; Vanderloo, L.M.; Keown-Stoneman, C.D.G.; Parkin, P.C.; Maguire, J.L.; Birken, C.S. The association between screen time and cardiometabolic risk in young children. Int. J. Behav. Nutr. Phys. Act. 2020, 17, 1-10. [CrossRef] [PubMed] 
15. Biddle, S.J.; Pearson, N.; Ross, G.M.; Braithwaite, R. Tracking of sedentary behaviours of young people: A systematic review. Prev. Med. 2010, 51, 345-351. [CrossRef]

16. Hancox, R.J.; Milne, B.J.; Poulton, R. Association between child and adolescent television viewing and adult health: A longitudinal birth cohort study. Lancet 2004, 364, 257-262. [CrossRef]

17. Steele, R.M.; Van Sluijs, E.; Cassidy, A.; Griffin, S.J.; Ekelund, U. Targeting sedentary time or moderate- and vigorous-intensity activity: Independent relations with adiposity in a population-based sample of 10-y-old British children. Am. J. Clin. Nutr. 2009, 90, 1185-1192. [CrossRef] [PubMed]

18. Sherry, A.P.; Pearson, N.; Ridgers, N.D.; Barber, S.E.; Bingham, D.D.; Nagy, L.C.; Clemes, S.A. activPAL-measured sitting levels and patterns in 9-10 years old children from a UK city. J. Public Health 2019, 41, 757-764. [CrossRef] [PubMed]

19. Birken, C.S.; Maguire, J.; Mekky, M.; Manlhiot, C.; Beck, C.E.; Jacobson, S.; Peer, M.; Taylor, C.; McCrindle, B.W.; Parkin, P.C. Parental factors associated with screen time in pre-school children in primary-care practice: A TARGet Kids! study. Public Health Nutr. 2011, 14, 2134-2138. [CrossRef]

20. Rundle, A.G.; Park, Y.; Herbstman, J.B.; Kinsey, E.W.; Wang, Y.C. COVID-19-Related School Closings and Risk of Weight Gain Among Children. Obesity 2020, 28, 1008-1009. [CrossRef]

21. Straker, L.; Howie, E.K.; Cliff, D.P.; Davern, M.T.; Engelen, L.; Gomersall, S.R.; Ziviani, J.; Schranz, N.; Olds, T.; Tomkinson, G.R. Australia and Other Nations Are Failing to Meet Sedentary Behaviour Guidelines for Children: Implications and a Way Forward. J. Phys. Act. Health 2016, 13, 177-188. [CrossRef] [PubMed]

22. Faught, E.L.; Ekwaru, J.P.; Gleddie, D.; Storey, K.E.; Asbridge, M.; Veugelers, P.J. The combined impact of diet, physical activity, sleep and screen time on academic achievement: A prospective study of elementary school students in Nova Scotia, Canada. Int. J. Behav. Nutr. Phys. Act. 2017, 14, 1-13. [CrossRef] [PubMed]

23. Dumuid, D.; Olds, T.; Martín-Fernández, J.-A.; Lewis, L.K.; Cassidy, L.; Maher, C. Academic Performance and Lifestyle Behaviors in Australian School Children: A Cluster Analysis. Health Educ. Behav. 2017, 44, 918-927. [CrossRef]

24. Hinkley, T.; Verbestel, V.; Ahrens, W.; Lissner, L.; Molnar, D.; Moreno, L.A.; Pigeot, I.; Pohlabeln, H.; Reisch, L.A.; Russo, P.; et al. Early childhood electronic media use as a predictor of poorer well-being: A prospective cohort study. JAMA Pediatr. 2014, 168, 485-492. [CrossRef] [PubMed]

25. Australian Government, Department of Health. Australian 24-Hour Movement Guidelines for Children and Young People (5-17 years) - An Integration of Physical Activity, Sedentary Behaviour and Sleep.; Commonwealth of Australia, Department of Health, Australian Government: Canberra, NSW, Australia, 2019.

26. Tremblay, M.S.; Carson, V.; Chaput, J.-P.; Gorber-Conner, S.; Dinh, T.; Duggan, M.; Faulkner, G.; Gray, C.E.; Gruber, R.; Janson, K.; et al. Canadian 24-Hour Movement Guidelines for children and youth: An Integration of Physical Activity, Sedentary Behaviour, and Sleep. Appl. Physiol. Nutr. Metab. 2016, 41, 311-327. [CrossRef] [PubMed]

27. WHO. Guidelines on Physical Activity, Sedentary Behaviour and Sleep for Children under 5 Years of Age: Web Annex: Evidence Profiles; World Health Organization: Geneva, Switzerland, 2019.

28. Pfeiffer, K.; Banzer, W.; Ferrari, N.; Füzéki, E.; Geidl, W.; Graf, C.; Hartung, V.; Klamroth, S.; Völker, K.; Vogt, L. Empfehlung für Bewegung [Guidelines for physical activitiy]. In Nationale Empfehlungen Für Bewegung und Bewegungsförderung National Guidelines for Physical Activity And Physical Activity Promotion; Rütten, A., Pfeiffer, K., Eds.; FAU Erlangen-Nürnberg: Erlangen-Nürnberg, Germany, 2016; pp. 17-31.

29. Tremblay, M.S.; Leblanc, A.G.; Carson, V.; Choquette, L.; Gorber, S.C.; Dillman, C.; Duggan, M.; Gordon, M.J.; Hicks, A.; Janssen, I.; et al. Canadian Sedentary Behaviour Guidelines for the Early Years (aged 0-4 years). Appl. Physiol. Nutr. Metab. 2012, 37, 370-380. [CrossRef] [PubMed]

30. Väistö, J.; Eloranta, A.-M.; Viitasalo, A.; Tompuri, T.T.; Lintu, N.; Karjalainen, P.; Lampinen, E.-K.; Ågren, J.; Laaksonen, D.E.; Lakka, H.-M.; et al. Physical activity and sedentary behaviour in relation to cardiometabolic risk in children: Cross-sectional findings from the Physical Activity and Nutrition in Children (PANIC) Study. Int. J. Behav. Nutr. Phys. Act. 2014, 11, 55. [CrossRef]

31. Lee, E.-Y.; Hesketh, K.D.; Hunter, S.; Kuzik, N.; Rhodes, R.E.; Rinaldi, C.M.; Spence, J.C.; Carson, V. Meeting new Canadian 24-Hour Movement Guidelines for the Early Years and associations with adiposity among toddlers living in Edmonton, Canada. BMC Public Health 2017, 17, 155-165. [CrossRef]

32. Chaput, J.-P.; Colley, R.C.; Aubert, S.; Carson, V.; Janssen, I.; Roberts, K.C.; Tremblay, M.S. Proportion of preschool-aged children meeting the Canadian 24-Hour Movement Guidelines and associations with adiposity: results from the Canadian Health Measures Survey. BMC Public Health 2017, 17, 829. [CrossRef] 
33. Howie, E.K.; Joosten, J.; Harris, C.J.; Straker, L.M. Associations between meeting sleep, physical activity or screen time behavior guidelines and academic performance in Australian school children. BMC Public Health 2020, 20, 520. [CrossRef]

34. Gallant, F.; Thibault, V.; Hebert, J.; Gunnell, K.E.; Bélanger, M. One size does not fit all: Identifying clusters of physical activity, screen time, and sleep behaviour co-development from childhood to adolescence. Int. J. Behav. Nutr. Phys. Act. 2020, 17, 1-14. [CrossRef] [PubMed]

35. Tripathi, M.; Mishra, S.K. Screen time and adiposity among children and adolescents: A systematic review. J. Public Health 2020, 28, 227-244. [CrossRef]

36. Saunders, T.J.; Tremblay, M.S.; Mathieu, M.-Ė.; Henderson, M.; O’Loughlin, J.; Tremblay, A.; Chaput, J.-P.; on behalf of the QUALITY cohort research group. Associations of Sedentary Behavior, Sedentary Bouts and Breaks in Sedentary Time with Cardiometabolic Risk in Children with a Family History of Obesity. PLoS ONE 2013, 8, e79143. [CrossRef]

37. Biddle, S.J.H.; Bengoechea, E.G.; Wiesner, G. Sedentary behaviour and adiposity in youth: A systematic review of reviews and analysis of causality. Int. J. Behav. Nutr. Phys. Act. 2017, 14, 1-21. [CrossRef] [PubMed]

38. Keane, E.; Li, X.; Harrington, J.M.; Fitzgerald, A.P.; Perry, I.J.; Kearney, P.M. Physical Activity, Sedentary Behavior and the Risk of Overweight and Obesity in School-Aged Children. Pediatr. Exerc. Sci. 2017, 29, 408-418. [CrossRef] [PubMed]

39. Thorp, A.A.; Owen, N.; Neuhaus, M.; Dunstan, D.W. Sedentary behaviors and subsequent health outcomes in adults: A systematic review of longitudinal studies, 1996-2011. Am. J. Prev. Med. 2011, 41, 207-215. [CrossRef]

40. Clemes, S.A.; Bingham, D.D.; Pearson, N.; Chen, Y.-L.; Edwardson, C.; McEachan, R.R.C.; Tolfrey, K.; Cale, L.; Richardson, G.; Fray, M.; et al. Stand Out in Class: Restructuring the classroom environment to reduce sedentary behaviour in 9-10-year-olds-Study protocol for a pilot cluster randomised controlled trial. Pilot Feasibility Stud. 2018, 4, 103. [CrossRef]

41. Lloyd, J.; Creanor, S.; Logan, S.; Green, C.; Dean, S.G.; Hillsdon, M.; Abraham, C.; Tomlinson, R.; Pearson, V.; Taylor, R.S.; et al. Effectiveness of the Healthy Lifestyles Programme (HeLP) to prevent obesity in UK primary-school children: A cluster randomised controlled trial. Lancet Child Adolesc. Health 2018, 2, 35-45. [CrossRef]

42. Carducci, A.; Casini, B.; Donzelli, G.; Verani, M.; Bruni, B.; Ceretti, E.; Zani, C.; Carraro, E.; Bonetta, S.; Bagordo, F.; et al. Improving awareness of health hazards associated with air pollution in primary school children: Design and test of didactic tools. Appl. Environ. Educ. Commun. 2016, 15, 247-260. [CrossRef]

43. Bartholomew, L.K.; Parcel, G.S.; Kok, G.; Gottlieb, N.H. Intervention Mapping Steps. In Planning Health Promotion Programs: An Intervention Mapping Approach; Bartholomew, L.K., Parcel, G.S., Kok, G., Gottlieb, N.H., Eds.; Jossey-Bass: San Francisco, CA, USA, 2006; pp. 191-472.

44. Wartha, O.; Koch, B.; Kobel, S.; Drenowatz, C.; Kettner, S.; Schreiber, A.; Wirt, T.; Kesztyüs, D.; Steinacker, J.M. Entwicklung und Implementierung eines landesweiten Multiplikatorensystems zur flächendeckenden Umsetzung des schulbasierten Präventionsprogramms "Komm mit in das gesunde Boot-Grundschule" Development and implementation of a state-wide "train-the-trainer" model of the school-based prevention programme "Join the Healthy Boat-Primary School". Gesundheitswesen 2014, 76, 655-661.

45. Bandura, A. Social Cognitive Theory: An Agentic Perspective. Annu. Rev. Psychol. 2000, 52, 1-26. [CrossRef] [PubMed]

46. Bronfenbrenner, U. Handbuch Bildungs-und Erziehungssoziologie Handbook of Sociology of Education; Bauer, U., Bittlingmayer, U., Scherr, A., Eds.; VS Verlag für Sozialwissenschaften: Wiesbaden, Germany, 2012; pp. 167-176.

47. Wartha, O.; Lämmle, C.; Kobel, S.; Wirt, T.; Steinacker, J.M. Aufbau des Bewegungsmoduls des schulbasierten Gesundheitsförderprogramms „Komm mit in das gesunde Boot“: Development of the activity module of the school based health promotion programme "Join the Healthy Boat". Dtsch. Z. Sportmed. 2017, 68, 20-26. [CrossRef]

48. Dreyhaupt, J.; Koch, B.; Wirt, T.; Schreiber, A.; Brandstetter, S.; Kesztyüs, D.; Wartha, O.; Kobel, S.; Kettner, S.; Prokopchuk, D.; et al. Evaluation of a health promotion program in children: Study protocol and design of the cluster-randomized Baden-Wuerttemberg primary school study [DRKS-ID: DRKS00000494]. BMC Public Health 2012, 12, 157. [CrossRef] [PubMed] 
49. Stewart, A.; Marfell-Jones, M.; Olds, T.; de Ridder, H. International Standards for Anthropometric Assessment; ISAK: Lower Hutt, New Zealand, 2011.

50. Kromeyer-Hauschild, K.; Wabitsch, M.; Kunze, D.; Geller, F.; Geisz, H.C.; Hesse, V.; Von Hippel, A.; Jaeger, U.; Johnsen, D.; Korte, W.; et al. Perzentile für den Body-Mass-Index für das Kindes- und Jugendalter unter Heranziehung verschiedener deutscher Stichproben (Percentiles of body mass index in children and adolescents evaluated from different regional German studies). Mon. Kinderheilkd. 2001, 149, 807-818. [CrossRef]

51. Corder, K.; Brage, S.; Mattocks, C.; Ness, A.R.; Riddoch, C.; Wareham, N.J.; Ekelund, U. Comparison of Two Methods to Assess PAEE during Six Activities in Children. Med. Sci. Sports Exerc. 2007, 39, 2180-2188. [CrossRef]

52. Addy, C.; Trilk, J.L.; Dowda, M.; Byun, W.; Pate, R.R. Assessing Preschool Children's Physical Activity: How Many Days of Accelerometry Measurement. Pediatr. Exerc. Sci. 2014, 26, 103-109. [CrossRef]

53. Corder, K.; Brage, S.; Wareham, N.J.; Ekelund, U. Comparison of PAEE from Combined and Separate Heart Rate and Movement Models in Children. Med. Sci. Sports Exerc. 2005, 37, 1761-1767. [CrossRef]

54. Tremblay, M.S.; Aubert, S.; Barnes, J.D.; Saunders, T.J.; Carson, V.; Latimer-Cheung, A.E.; Chastin, S.; Altenburg, T.M.; Chinapaw, M.J.M. Sedentary Behavior Research Network (SBRN) - Terminology Consensus Project process and outcome. Int. J. Behav. Nutr. Phys. Act. 2017, 14, 1-17. [CrossRef]

55. Kurth, B.-M.; Rosario, A.S. Übergewicht und Adipositas bei Kindern und Jugendlichen in Deutschland [Overweight and obesity in children and adolescents in Germany]. Bundesgesundheitsblatt Gesundheitsforschung Gesundheitsschutz 2010, 53, 643-652. [CrossRef]

56. Kobel, S.; Wirt, T.; Schreiber, A.; Kesztyüs, D.; Kettner, S.; Erkelenz, N.; Wartha, O.; Steinacker, J.M. Intervention effects of a school-based health promotion programme on obesity related behavioural outcomes. J. Obes. 2014, 2014, 4762230. [CrossRef]

57. Van Kann, D.H.H.; Kremers, S.P.J.; de Vries, N.K.; de Vries, S.I.; Jansen, M.W.J. The effect of a school-centred multicomponent intervention on daily physical activity and sedentary behaviour in primary school children: The Active Living study. Prev. Med. 2016, 89, 64-69. [CrossRef] [PubMed]

58. Janssen, X.; Mann, K.D.; Basterfield, L.; Parkinson, K.N.; Pearce, M.S.; Reilly, J.K.; Adamson, A.J.; Reilly, J.J. Development of sedentary behaviour across childhood and adolescence: Longitudinal analysis of the Gateshead Millennium Study. Int. J. Behav. Nutr. Phys. Act. 2016, 13, 88. [CrossRef] [PubMed]

59. Young, D.R.; Hivert, M.-F.; Alhassan, S.; Camhi, S.M.; Ferguson, J.F.; Katzmarzyk, P.T.; Lewis, C.E.; Owen, N.; Perry, C.K.; Siddique, J.; et al. Sedentary Behavior and Cardiovascular Morbidity and Mortality: A Science Advisory From the American Heart Association. Circulation 2016, 134, e262-e279. [CrossRef] [PubMed]

60. Chesham, R.A.; Booth, J.N.; Sweeney, E.L.; Ryde, G.C.; Gorely, T.; Brooks, N.E.; Moran, C.N. The Daily Mile makes primary school children more active, less sedentary and improves their fitness and body composition: A quasi-experimental pilot study. BMC Med. 2018, 16, 64. [CrossRef]

61. Riiser, K.; Richardsen, K.R.; Haugen, A.L.H.; Lund, S.; Løndal, K. Active play in ASP-a matched-pair cluster-randomised trial investigating the effectiveness of an intervention in after school programmes for supporting children's physical activity. BMC Public Health 2020, 20, 500. [CrossRef]

62. Kallio, J.; Hakonen, H.; Syväoja, H.; Kulmala, J.; Kankaanpää, A.; Ekelund, U.; Tammelin, T.H. Changes in physical activity and sedentary time during adolescence: Gender differences during weekdays and weekend days. Scand. J. Med. Sci. Sports 2020, 30, 1265-1275. [CrossRef]

63. Hilpert, M.; Brockmeier, K.; Dordel, S.; Koch, B.; Weiß, V.; Ferrari, N.; Tokarski, W.; Graf, P.D.D.C. Sociocultural Influence on Obesity and Lifestyle in Children: A Study of Daily Activities, Leisure Time Behavior, Motor Skills, and Weight Status. Obes. Facts 2017, 10, 168-178. [CrossRef]

64. McMurray, R.G.; Berry, D.C.; Schwartz, T.A.; Hall, E.G.; Neal, M.N.; Li, S.; Lam, D. Relationships of physical activity and sedentary time in obese parent-child dyads: A cross-sectional study. BMC Public Health 2015, 16, 124. [CrossRef]

65. Jago, R.; Solomon-Moore, E.; Macdonald-Wallis, C.; Thompson, J.L.; Lawlor, D.A.; Sebire, S.J. Association of parents' and children's physical activity and sedentary time in Year 4 (8-9) and change between Year 1 (5-6) and Year 4: A longitudinal study. Int. J. Behav. Nutr. Phys. Act. 2017, 14, 110. [CrossRef]

66. Fuemmeler, B.F.; Anderson, C.B.; Mâsse, L.C. Parent-child relationship of directly measured physical activity. Int. J. Behav. Nutr. Phys. Act. 2011, 8, 17. [CrossRef] 
67. Raychaudhuri, M.; Sanyal, D. Childhood obesity: Determinants, evaluation, and prevention. Indian J. Endocrinol. Metab. 2012, 16, S192-S194. [PubMed]

68. Lambrinou, C.-P.; On Behalf of the Feel4Diabetes-Study Group; Androutsos, O.; Karaglani, E.; Cardon, G.; Huys, N.; Wikström, K.; Kivelä, J.; Ko, W.; Karuranga, E.; et al. Effective strategies for childhood obesity prevention via school based, family involved interventions: A critical review for the development of the Feel4Diabetes-study school based component. BMC Endocr. Disord. 2020, 20, 52. [CrossRef]

69. Santaliestra-Pasías, A.M.; Mouratidou, T.; Verbestel, V.; Bammann, K.; Molnar, D.; Sieri, S.; Siani, A.; Veidebaum, T.; Mårild, S.; Lissner, L.; et al. Physical activity and sedentary behaviour in European children: The IDEFICS study. Public Health Nutr. 2013, 17, 2295-2306. [CrossRef]

70. Saunders, T.J.; Vallance, J.K. Screen Time and Health Indicators Among Children and Youth: Current Evidence, Limitations and Future Directions. Appl. Health Econ. Health Policy 2016, 15, 323-331. [CrossRef]

71. Hale, L.; Guan, S. Screen time and sleep among school-aged children and adolescents: A systematic literature review. Sleep Med. Rev. 2015, 21, 50-58. [CrossRef] [PubMed]

72. Verbestel, V.; De Henauw, S.; Bammann, K.; Barba, G.; Hadjigeorgiou, C.; Eiben, G.; Konstabel, K.; Kovaács, E.; Pitsiladis, Y.; Reisch, L.; et al. Are context-specific measures of parental-reported physical activity and sedentary behaviour associated with accelerometer data in 2-9-year-old European children? Public Health Nutr. 2014, 18, 860-868. [CrossRef] [PubMed]

73. Hoffmann, B.; Kobel, S.; Wartha, O.; Kettner, S.; Dreyhaupt, J.; Steinacker, J.M. High sedentary time in children is not only due to screen media use: A cross-sectional study. BMC Pediatr. 2019, 19, 1-9. [CrossRef]

74. Khambalia, A.Z.; Dickinson, S.; Hardy, L.L.; Gill, T.; Baur, L.A. A synthesis of existing systematic reviews and meta-analyses of school-based behavioural interventions for controlling and preventing obesity. Obes. Rev. 2012, 13, 214-233. [CrossRef]

75. Jago, R.; Rawlins, E.; Kipping, R.; Wells, S.; Chittleborough, C.; Peters, T.J.; Mytton, J.; Lawlor, D.A.; Campbell, R. Lessons learned from the AFLY5 RCT process evaluation: Implications for the design of physical activity and nutrition interventions in schools. BMC Public Health 2015, 15, 1-10. [CrossRef]

76. Sharma, M. International school-based interventions for preventing obesity in children. Obes. Rev. 2006, 8, 155-167. [CrossRef]

77. Marild, S.; Russo, P.; Veidebaum, T.; Tornaritis, M.; De Henauw, S.; De Bourdeaudhuij, I.; Molnár, D.; Moreno, L.A.; Bramsved, R.; Peplies, J.; et al. Impact of a community based health-promotion programme in 2- to 9-year-old children in Europe on markers of the metabolic syndrome, the IDEFICS study. Obes. Rev. 2015, 16, 41-56. [CrossRef] [PubMed]

Publisher's Note: MDPI stays neutral with regard to jurisdictional claims in published maps and institutional affiliations.

(C) 2020 by the authors. Licensee MDPI, Basel, Switzerland. This article is an open access article distributed under the terms and conditions of the Creative Commons Attribution (CC BY) license (http://creativecommons.org/licenses/by/4.0/). 